LeIfSON, E. \& HUGH, R. (1954). J. gen. Microbiol. 11, 512-513.

\title{
Alcaligenes denitrificans n.sp.
}

\author{
By E. LEIFSON AND R. HUGH \\ Stritch School of Medicine and Graduate School, \\ Loyola University, Chicago, Illinois, U.S.A.
}

SUMMARY: A new species of the genus Alcaligenes is described which is able to produce gas from nitrate.

The ability to reduce nitrate with formation of nitrogen gas is common to several kinds of bacteria, particularly the non-fermentative Gram-negative rods. The named bacteria of this type about which we have personal knowledge are Pseudomonas aeruginosa, $\boldsymbol{P}$. stutzeri and Malleomyces pseudomallei. Various strains of Brucella of all species may produce a small amount of gas from nitrate. The phenomenon appears to be most common among the polar flagellated organisms of the Pseudomonas genus.

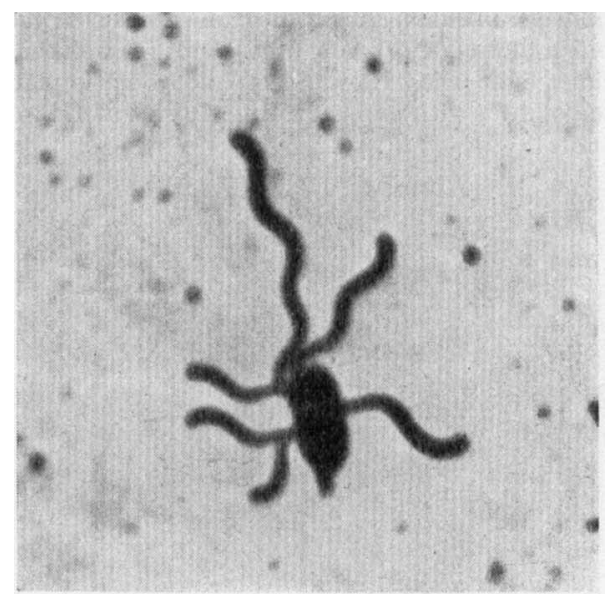

Fig. 1. Alcaligenes denitrificans n.sp. showing typical flagellation. Leifson flagella stain (Leifson, 1951). Photomicrograph, $\times 3600$.

Among some 100 strains of peritrichously flagellated Gram-negative rods in our collection are eight which produce gas from nitrate. Six of these are old stock cultures from various sources; all oxidize glucose and some xylose. The other two strains were received from L. R. Fredrich (Purdue University) and were isolated from soil. These two strains appear to be alike and do not attack any of the carbohydrates tested. They appear to be typical of the Alcaligenes genus. We suggest that they be recognized as a species of Alcaligenes with the name Alcaligenes denitrificans n.sp. 


\section{DESCRIPTION}

Morphology. Rod shaped, $\mathbf{0} \cdot \mathbf{5}$ by $\mathbf{1} \cdot 0 \mu$, ends rounded, usually occurring singly or in short chains. Motile. Gram-negative. Flagellation peritrichous with 3 to 10 flagella/organism. Flagella all of one type. Measurement of 20 flagella gave a mean flagellar wavelength (spiral period) of $2 \cdot 46 \pm 0.044 \mu$, and a mean flagellar amplitude (spiral width) of $0.49 \pm 0.024 \mu$. In Fig. 1 is reproduced a photomicrograph showing the flagellation of the organism.

Cultural characteristics. Colonies on agar smooth, edges entire, semi-translucent. Growth on agar slants abundant, smooth, colourless and semi-translucent. Growth in agar stab confined mainly to or near the surface. Growth in broth uniformly turbid, moderate pellicle formation. No growth in nutrient broth under anaerobic conditions. Temperature relations, mesophilic; $\mathrm{pH}$ relations, neutrophilic; oxygen relations, aerobic; pigmentation, none.

Physiological characteristics. Carbohydrates not attacked include lactose, sucrose, glucose, maltose, mannitol, xylose, arabinose; urea not hydrolyzed; gelatin not liquefied; $\mathrm{H}_{2} \mathrm{~S}$ not produced; citrate utilized in Simmons citrate agar; nitrate reduced with formation of nitrite and/or nitrogen gas; litmus milk-turns blue.

Habitat. Isolated from soil.

Type strain. A culture has been deposited in the National Collection of Type Cultures, London (NCTC 8582).

\section{REFERENCE}

LEIFson, H. (1951). Staining, shape and arrangement of bacterial flagella. J. Bact. 62,877 .

(Received 15 July 1954) 